Article

\title{
Effect of Ionic Liquids as the Mobile Phase Additives on the HPLC Resolution of Four Active Compounds from Sophora flavescens Ait
}

\author{
Minglei Tian, Junyu Liu and Kyung Ho Row *
}

Department of Chemical Engineering, Inha University, Incheon, 402-751, Korea

* Author to whom correspondence should be addressed; E-mail: rowkho@inha.ac.kr;

Tel.: +82-32-860-7470

Received: 17 April 2009; in revised form: 7 May 2009 / Accepted: 2 June 2009 /

Published: 11 June 2009

\begin{abstract}
The retention behaviour of four active compounds from Sophora Flavescens Ait using three ionic liquids as mobile phase modifiers was examined. The effect of the $\mathrm{pH}$ and the amount of ionic liquid modifier on the retention of these compounds was determined in methanol/water (v/v) as the mobile phase containing different ionic liquids ranging in concentration from $0.1 \mathrm{mmol} / \mathrm{L}$ to $3.0 \mathrm{mmol} / \mathrm{L}$. The ionic liquids showed promise as additives in high-performance liquid chromatography.
\end{abstract}

Keywords: ionic liquid; retention; resolution; HPLC; Sophora flavescens Ait

\section{Introduction}

Ionic liquids (ILs) are organic salts that are liquids at ambient temperatures. Unlike traditional solvents, which can be described as molecular liquids, ionic liquids are composed of ions. Their unique properties such as non-volatility, non-flammability, and excellent chemical and thermal stability, make them an environmentally attractive alternative to conventional organic solvents [1-5]. Room temperature ionic liquids are gaining wide recognition as novel solvents in chemistry. Examination of their potential application in analytical chemistry, especially in separating analytes, is warranted because ILs offer some unique properties, such as negligible vapor pressure, good thermal stability, tunable viscosity, strong polarity, and miscibility with water and organic solvents, as well as good extractability for various organic compounds and metal ions [6]. 
Reversed phase HPLC is widely used as a standard analytical technque, and a number of stationary phases are commercially available [7]. In a chromatographic column, injected materials are separated based on their differences in the solvation and partition in a stationary phase [8]. HPLC is used for the separation, purification, collection of the single components, the qualitative and quantitative analysis of the adsorption, division, ion exchange, and exclusion effects when the mobile phase passes through the solid phase.

Sophora flavescens Ait (SFA) has been used since ancient times as a traditional Chinese herb to treat many diseases. It has recently attracted a great deal of attention in natural medication research on account of its high pharmacological activity. Sophora alkaloids, including matrine (MT), oxymatrine (OMT), sophocarpine (SC), sophoridine (SRI) and others [9] are its chief active components. Studies of its pharmacological effects have shown that SRI has wide range of pharmacological effects including anti-arrhythmic [10], anti-tumor [11], immunological enhancement [12], immunosuppressant [13], antiseptic and central nervous system excitation properties [14]. However, there are few reports showing that these four compounds can be separated at the same time, as it is difficult to separate these four alkaloids simultaneously due to their similar chemical structures (Figure 1). Therefore, a simple and effective analytical method for their simultaneous determination is needed.

Figure 1. Chemical structure of the four compounds.

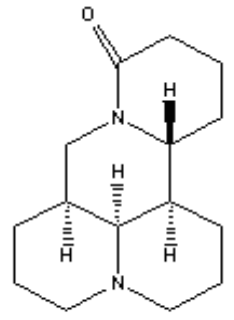

Matrine

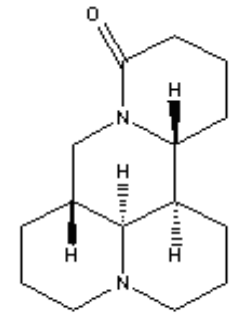

Sophoridine

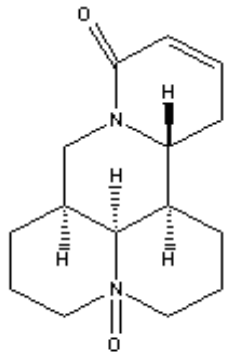

Oxymatrine

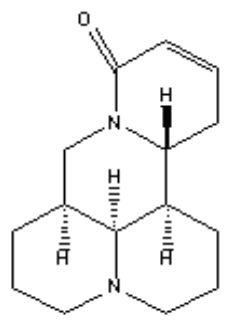

Sophocarpine

This study examined the potential applications of different ionic liquids as additives in the separation of four compounds from SFA. Three types of ionic liquids were used as mobile phase additives in reversed-phase HPLC (RPHPLC) and the retention factors of the four compounds were determined using methanol/water as the mobile phase. The effects of the concentration of ionic liquids with their nature on the chromatographic retention and separation were examined.

\section{Results and Discussion}

In this study the retention factor was calculated using eq. (1):

$$
k=\frac{t_{R}-t_{0}}{t_{0}}
$$

where $t_{0}$ is the dead-time, $t_{R}$ is the retention time, and $k$ is the retention factor, respectively.

The resolution $(\mathrm{R})$ was calculated using the eq. (2):

$$
R=\frac{t_{R 2}-t_{R 1}}{\left(w_{2}+w_{1}\right) / 2}=\frac{2 \Delta t}{w_{2}+w_{1}}
$$


where $t_{\mathrm{R} 1}$ and $t_{\mathrm{R} 2}$ are the retention times of the first and second peak, respectively, and $\mathrm{w}_{1}$ and $\mathrm{w}_{2}$ are the corresponding peak widths.

\subsection{Effect of ionic liquids types and concentrations on retention of four compounds}

As reported by other authors [15], ionic liquid cations in the eluent will adsorb onto the $\mathrm{C}_{18}$ column packings and cause changes in their properties. Imidazolium cations can interact with silanol groups and compete with the polar group of analytes for the silanol groups on the alkylsilica surface in a column. Therefore, it can effectively shield residual silanols and improve the peak shapes, while also decreasing the retention time of the analytes. Another application of ionic liquid in chromatography is also for the suppression of deleterious effects of free silanols by using imidazolium tetrafluoroborate ionic liquid [16].

In this step, the influences of the three types of ionic liquids with different concentrations $(0.1$ $3.0 \mathrm{mmol} / \mathrm{L}$ ) were tested. Figure 2 shows there chromatograms of mixture of four standard compounds with different mobile phases. In the beginning, the target compounds could not be separated well without a modifier (Figure 2A). With the addition of diethylamine and IL to the mobile phase, the resolution and peak shape were obviously improved (Figure 2 (B)) and the IL could decrease the retention times of the four compounds (Figure 2 (C)).

Figure 2. The chromatograms of standard compounds of OMT, SRI, SC and MT in methonal/water $(45 / 55, \mathrm{v} / \mathrm{v})$ as the mobile phase without modifier (A), with diethylamine (B) and with diethylamine and IL (C).
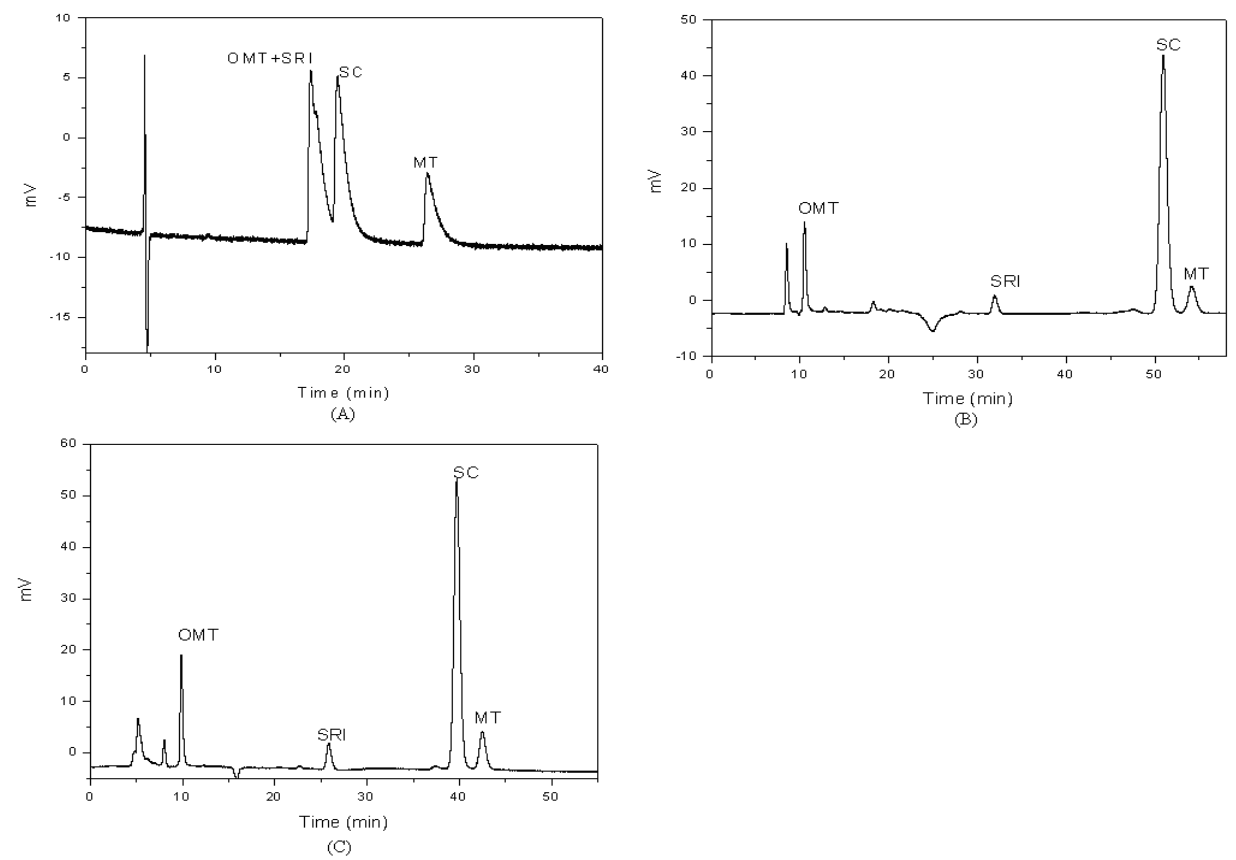

When the ILs were used, the four compounds can be separated except with $[\mathrm{OMIM}]\left[\mathrm{BF}_{4}\right]$ as the mobile phase additive, so the $\mathrm{pH}$ of the mobile phase containing [OMIM] $\left[\mathrm{BF}_{4}\right.$ ] was modified in further experiments. Figures 3(A) and 3(B) show the results with different concentrations of [HMIM] $\left[\mathrm{BF}_{4}\right]$ and $[\mathrm{BMIM}]\left[\mathrm{BF}_{4}\right]$. From these figures, we can see that the retention factor of the four compounds 
decreased as the concentration of ionic liquids increased. It appears that $[\mathrm{HMIM}]\left[\mathrm{BF}_{4}\right]$ provides a better resolution with a decrease in alkyl chain length and the optimum concentration of the ionic liquid was $0.1 \mathrm{mmol} / \mathrm{L}$.

Figure 3. Effect of $k$ of four compounds by using different concentrations of [BMIM] $\left.\mathrm{BF}_{4}\right]$ (A) and $[\mathrm{HMIM}]\left[\mathrm{BF}_{4}\right](\mathrm{B})$ as the mobile phase additives.

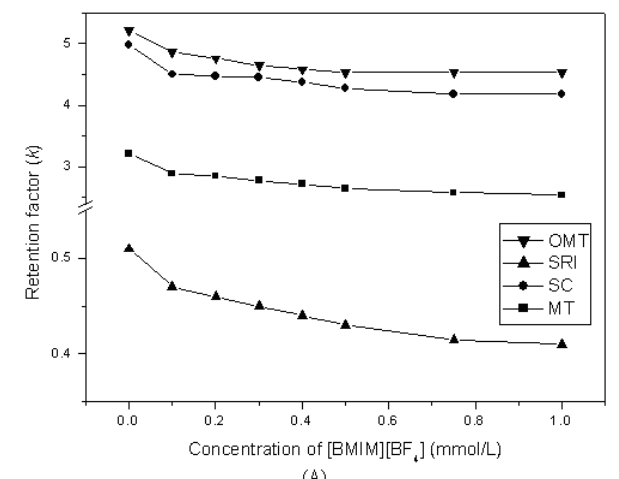

(A)

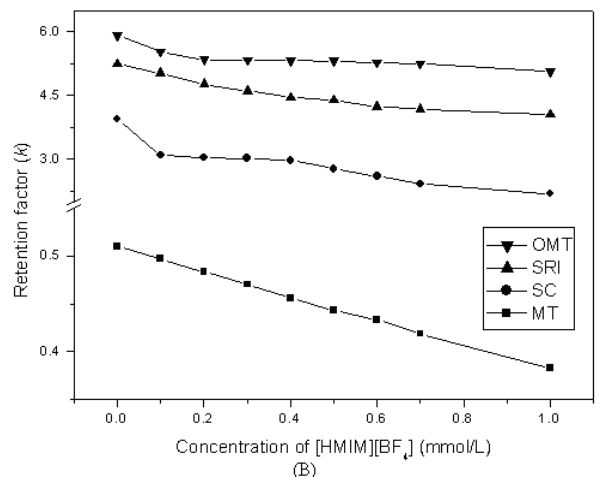

(B)

\subsection{Effect of $p H$ of mobile phases with ionic liquids on retention of four compounds}

The $\mathrm{pH}$ increased slightly when the ionic liquids were added to the mobile phase because the tetrafluoroborate $\left(\left[\mathrm{BF}_{4}\right]\right)$ is weak basic anion. However, the four compounds were alkaloids, so the mobile phase with a $\mathrm{pH}>7.0$ was more suitable for separating them. According to this condition, $\mathrm{pH}$ of the mobile phases with $0.1 \mathrm{mmol} / \mathrm{L}$ ionic liquids were examined (Figure 4).

Figure 4. Effect of $k$ of four compounds by using different $\mathrm{pH}$ of the mobile phase with $0.1 \mathrm{mM}$ of $[\mathrm{HMIM}]\left[\mathrm{BF}_{4}\right] \mathbf{( A ) ,}[\mathrm{BMIM}]\left[\mathrm{BF}_{4}\right] \mathbf{( B )}$ and $[\mathrm{OMIM}]\left[\mathrm{BF}_{4}\right](\mathbf{C})$.

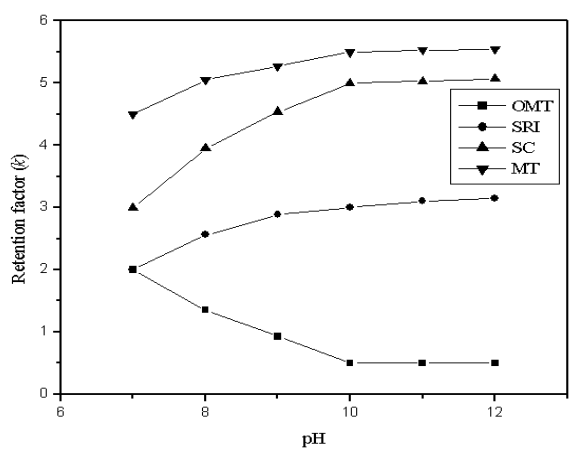

(A)

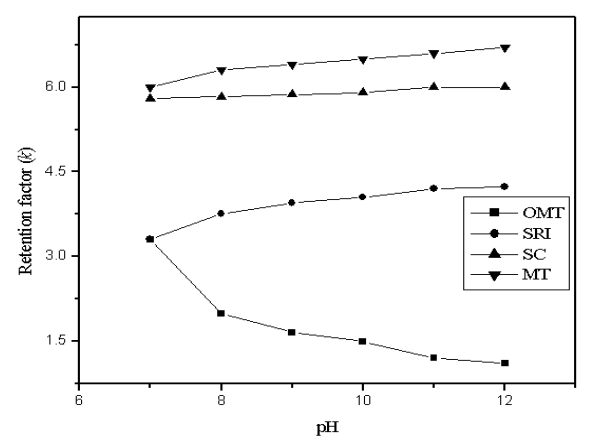

(C)

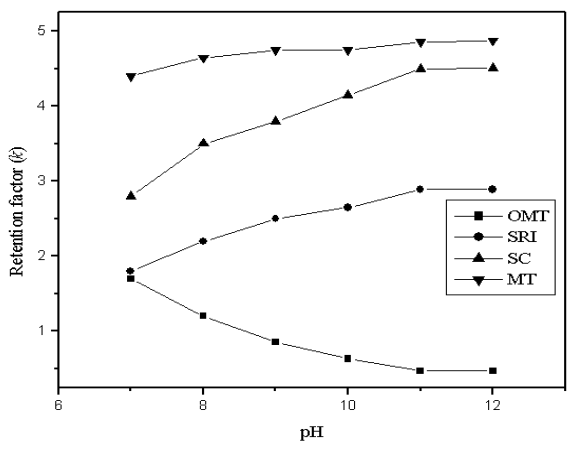

(B) 
Figure 5 shows the resolution between each two compounds. The retention factors of OMT, SRI and SC increased with the concentration of diethylamine increasing except MT. The MT can be eluted out earlier but can not be separated from other compounds with higher $\mathrm{pH}$. The result revealed that $\mathrm{pH}=11.3$ was the optimum condition for separation these four compounds.

Figure 5. Effect of resolution of four compounds by using different $\mathrm{pH}$ of the mobile phase

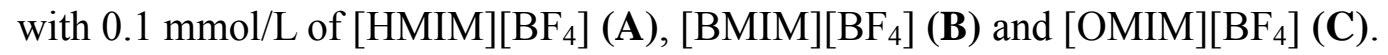

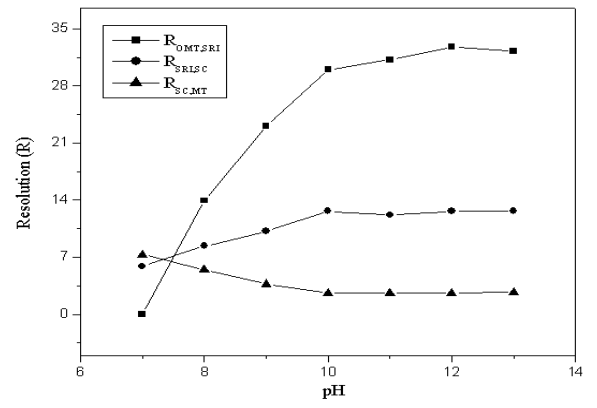

(A)

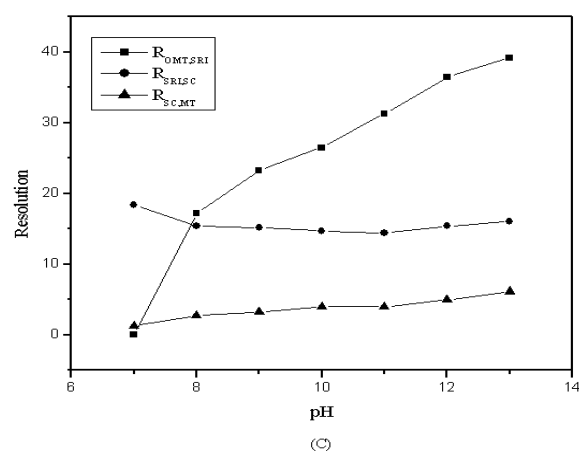

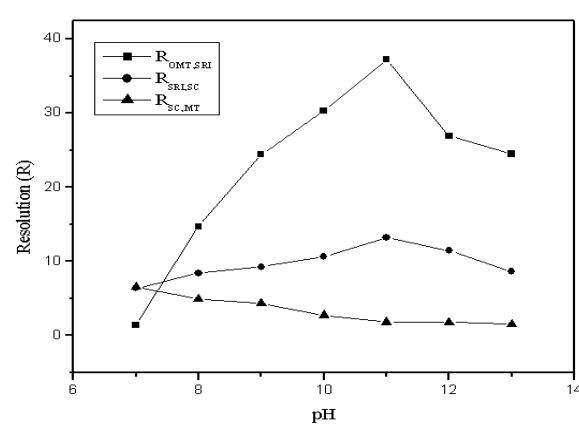

(B)

According to the results obtained in this experiment, the optimum mobile phase with additives was methanol/water $(45 / 55, \mathrm{v} / \mathrm{v})$ with $0.1 \mathrm{mM}[\mathrm{HMIM}]\left[\mathrm{BF}_{4}\right]$ at $\mathrm{pH}=11.3$. This condition was applied to separate the natural plant extract. Figure 6 shows that the four target compounds can be separated.

Figure 6. The chromatogram of four compounds in extract from SFA in methanol/water $(45 / 55, \mathrm{v} / \mathrm{v})$ as the mobile phase with $0.1 \mathrm{mM}[\mathrm{HMIM}]\left[\mathrm{BF}_{4}\right]$ at the $\mathrm{pH}=11.3$.

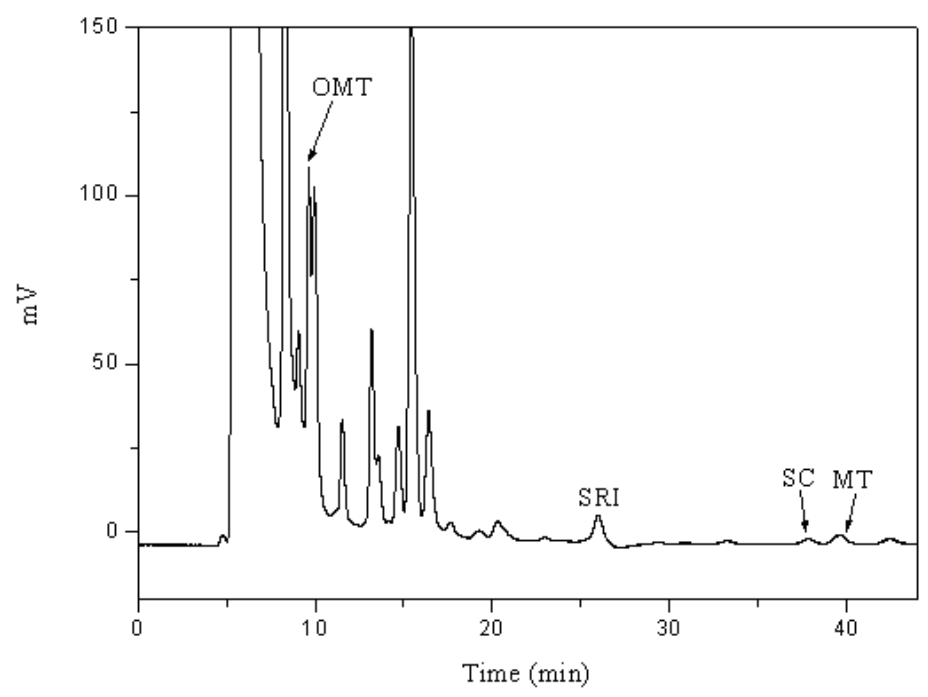




\subsection{Method Validation}

To ensure the specificity and selectivity of the condition, concentrations ranging from $5 \cdot 10^{-3}$ to $1.0 \mathrm{mg} / \mathrm{mL}$ were applied for standards solutions of the four compounds. The analyte peak area of the analytes was plotted against the corresponding concentrations, and calibration curves were constructed using the least-squares method. The calibration curves of the four compounds showed good linearity $\left(\mathrm{r}^{2}>0.998\right)$. The standard solutions were diluted and injected until the limit of detection (LOD) was obtained at a signal/noise ratio of 3, and $27 \mathrm{ng} / \mathrm{mL}, 35 \mathrm{ng} / \mathrm{mL}, 20 \mathrm{ng} / \mathrm{mL}$ and $32 \mathrm{ng} / \mathrm{mL}$ for OMT, SRI, $\mathrm{SC}$ and MT, respectively. Comparison with the real sample analysis verified that the values noted above were of acceptable precision and accuracy.

\section{Experimental Section}

\subsection{Chemical regents}

MT, OMT and SC were provided by the National Institute for The Control of Pharmaceutical and Biological Products of China, SRI was provided by Chengdu Mansite Biological Technology Co. Ltd., Sophora flavescens Ait was purchased from Anguo, Hebei, China (around August, 2008). Methanol, acetonitrile, $n$-propanol and diethylamine were all from Duksan Ltd., Korea. 1-Hexyl-3-methylimidazolium tetrafluoroborate ([HMIM] $\left.\left[\mathrm{BF}_{4}\right]\right)$, 1-butyl-3-methylimidazolium tetrafluoroborate $\left([\mathrm{BMIM}]\left[\mathrm{BF}_{4}\right]\right)$ and 1-octyl-3-methylimidazolium tetrafluoroborate ([OMIM] $\left.\left[\mathrm{BF}_{4}\right]\right)$ were purchased from C-TRI (Korea).

\subsection{Apparatus}

The chromatography system consisted of M930 Multi-solvent Delivery System, a variable wavelength M720 UV detector, the data processing was carried out with Autochrowin Ver. 1.42 (Young Lin Co. Korea) and a Rheodyne injector $\left(20 \mu \mathrm{L}\right.$ sample loop). A $\mathrm{C}_{18}$ column (250 $\mathrm{mm} \times$ $4.6 \mathrm{~mm}, 5 \mu \mathrm{m}$ ) was from RStech Corporation (Daejeon, Korea). Distilled water was filtered with a vacuum pump (Division of Millipore, Waters, U.S.A.) and filter (HA-0.45 $\mu \mathrm{m}$, Division of Millipore, Waters, U.S.A.) before use. All the solvents should be filtered (MFS-25, $0.2 \mu \mathrm{m}$, WHATMAN, U.S.A.) before injection into the HPLC system. Mobile phase was methanol/water $(45: 55, \mathrm{v} / \mathrm{v})$, the flow rate was $0.6 \mathrm{~mL} / \mathrm{min}$ and UV wavelength was $238 \mathrm{~nm}$.

\subsection{Preparation of Standard solutions and extracts from SFA}

Four standard compounds were mixed and dissolved in methanol to yield a final concentration of $0.25 \mathrm{mg} / \mathrm{mL}$. The SFA had been dried at $30^{\circ} \mathrm{C}$, sliced and crushed into powder and $1.0 \mathrm{~g}$ was mixed with $25.0 \mathrm{~mL}$ water for $1 \mathrm{hr}$ at $100^{\circ} \mathrm{C}$ temperature.

\section{Conclusions}

This paper discussed the effects of three ionic liquids as mobile phase additives for the HPLC separation of OMT, SRI, SC and MT from SFA. The length of the alkyl chain on the imidazolium ring has a significant inverse effect on the separation. Excellent separation condition of the four compounds 
was methanol/water $(45: 55, \mathrm{v} / \mathrm{v})$ with $0.1 \mathrm{mmol} / \mathrm{L}[\mathrm{HMIM}]\left[\mathrm{BF}_{4}\right]$ as the additive at $\mathrm{pH}=11.3$. The role of the ionic liquids is multiple and further research will be needed to explain some of the observed phenomena. In any case, ionic liquids show promising performance as additives in HPLC.

\section{Acknowledgements}

This work was supported by Korea Research Foundation (2009-0072787).

\section{References}

1. Yang, Z.; Pan, W. Ionic liquids: Green solvents for nonaqueous biocatalysis. Enzyme Microb. Technol. 2005, 37, 19-28.

2. Liu, J.; Jonsson, J.; Jiang, G. Application of ionic liquids in analytical chemistry. Trend Anal. Chem. 2005, 24, 20-27.

3. Zhao, D.; Wu, M.; Kou, Y.; Min, E. Ionic liquids: Applications in catalysis. Catal. Today 2002, 74, 157-189.

4. Gordon, C.M. New developments in catalysis using ionic liquids. Appl. Catal. 2001, A222, 101-117.

5. Sun, J.; Fujita, S.; Arai, M. Development in the green synthesis of cyclic carbonate from carbon dioxide using ionic liquids. J. Organomet. Chem. 2005, 690, 3490-3497.

6. Berthod, A.; Ruiz-Ángel, M.J.; Carda-Broch, S. Ionic liquids in separation techniques. J. Chromatogr. A 2008, 1184, 6-18.

7. Lee, Y.W.; So, M.S.; Lee, J.W.; Chung, S.T.; Row, K.H. Retention models of capacity factor with different compositions of organic modifier in RP-HPLC. Korean J. Chem. Eng. 1996, 13, 578-584.

8. Choi, Y.J.; Han, S.K.; Chung, S.T.; Row, K.H. Chromatographic separation of bupivacaine racemate by mathematical model with competitive Langmuir isotherm. Korean J. Chem. Eng. 2004, 21, 829-835.

9. Chen, X.S.; Wang, G.J.; Cai, X.; Yu, H.Y.; Hu, Y.P. Inhibition of hepatitis B virus by oxymatrine in vivo. World J. Gastroenterol. 2001, 7, 49-52.

10. Ma, L.; Wen, S.; Zhan, Y.; He, Y.; Liu, X.; Jiang. Anticancer effects of the Chinese medicine matrine on mutine hepatocellular carcinoma cells. J. Planta Med. 2008, 74, 245-251.

11. Liu, S.X.; Chiou, G.C. Effects of Chinese herbal products on mammalian retinal functions. J. Ocul. Pharmacol. Ther. 1996, 12, 377-386.

12. Jiang, H.; Hou, C.; Zhang, S.; Xie, H.; Zhou, W.; Jin, Q.; Cheng, X.; Qian, R.; Zhang, X. Matrine upregulates the cell cycle protein E2F-1 and triggers apoptosis via the mitochondrial pathway in K562 cells. Eur. J. Pharmacol. 2007, 559, 98-108.

13. Azzam, H.S.; Goertz, C.; Fritts, M.; Jonas, W.B. Natural products and chronic hepatitis C virus. Liver Int. 2007, 27, 17-25.

14. Yamazaki, M. The pharmacological studies on matrine and oxymatrine. Yakugaku Zasshi, 2000, 120, 1025-1033.

15. Polyakova, Y.; Koo, Y.M.; Row, K.H. Application of ionic liquids as mobile phase modifier in HPLC. Biotechnol. Bioprocess Eng. 2006, 11, 1-6. 
16. Zhang, W.; He, L.; Gu, Y.; Liu, X.; Jiang, S. Effect of ionic liquids as mobile phase additives on retention of catecholamines in reversed-phase high performance liquid chromatography. Anal. Lett. 2003, 36, 827-838.

Sample Availability: Samples of the compounds are available from the authors.

(C) 2009 by the authors; licensee Molecular Diversity Preservation International, Basel, Switzerland. This article is an open-access article distributed under the terms and conditions of the Creative Commons Attribution license (http://creativecommons.org/licenses/by/3.0/). 